\title{
NUCLEAR REACTIONS IN THE SUN
}

\author{
CLAUS ROLFS \\ Institut für Kernphysik \\ Universität Münster, Münster \\ Germany
}

Due to unfortunate personal circumstances, the author could not provide a written version of his contribution presented at the Conference. He suggest the interested readers to refer to a recent review :

Nuclear energy generation in the solar interior

P.D. Parker and C. Rolfs

Chapter 2 in : The Solar Interior and Atmosphere

eds. A.N. Cox, W.C. Livingston and M.S. Matthews

Space Science Series Book (University of Arizona)

The Editors 